\title{
Analysis on the factors of daily electricity sales of urban and rural residents in Hunan province
}

\author{
Yun Zhang ${ }^{1,2}$, Huifeng Yan ${ }^{1,2}$, Xiao Zhou ${ }^{3, *}$, and Jingyi Tang ${ }^{3}$ \\ ${ }^{1}$ Energy Internet Supply and Demand Operation Hunan Key Laboratory, 410000 Changsha, China \\ ${ }^{2}$ State Grid Hunan Electric Power Company Limited, Economic and Technical Research Institute, \\ 410000 Changsha, China \\ ${ }^{3}$ Hunan University, School of Economics and Trade, 410079 Changsha, China
}

\begin{abstract}
It's of practical significance to explore the internal law of the fluctuation of the daily electricity sales of the urban and rural residents in Hunan province for the electricity planning and resource allocation in Hunan province. In this paper, after considering the economic meaning of electricity sales changes, a variety of factors were selected to influence the electricity sales of urban and rural residents in Hunan province, and the monthly residential electricity demand model from 2014 to 2019 was constructed, and the gradual regression was carried out. The results show that the per capita disposable monthly income ( $d p i)$ and non-comfortable days ( $n c d$ ) have significant impacts on the electricity sales of urban and rural residents. And for every $1 \%$ increase in $d p i$ or for each additional day of non-comfort days per month, the domestic electricity sales of urban and rural residents will increase by $0.49 \%$ or $0.01 \%$. In addition, under high temperature and low temperature conditions, the influence of precipitation presents asymmetric characteristics.
\end{abstract}

\section{Introduction}

With the steady increase of urbanization and household income, the proportion of domestic electricity consumption of urban and rural residents in the social electricity sales in China is gradually increasing with an increasing growth amplitude, and its contribution to the growth rate of the total social electricity sales will also gradually increase. Residential electricity consumption is an important part of the application of electric energy. Explaining its influencing factors is helpful to solve the current energy shortage, environmental pollution and other problems. It is of great significance to achieve high-quality electricity consumption for residents and restrain households with high electricity consumption.

The use of electricity for urban and rural residents refers to the use of electricity for lighting and household appliances for urban and rural residents. Generally, the use of household appliances is related to household income and temperature. Studying the influence factors of the residents living electricity and exploring the inherent law of electricity has practical significance for the local city's electricity planning and resource allocation. Since China's power grid companies are strengthening energy and resources cooperation with

\footnotetext{
* Corresponding author: zhouxiao8868@163.com
} 
countries along the "One Belt And One Road", and have realized the interconnection with the power grids of Southeast Asian countries, the study of Hunan Province, which has similar economic level, has prospective reference significance. Based on this, this paper selects the factors of the electricity by urban and rural residents to conduct an impact analysis on the internal and external factors of the electricity by urban and rural residents in Hunan province respectively, and carries out a fitting for the electricity sold in Hunan province from January 2014 to June 2019.

\section{Literature review}

In recent years, the research on the influencing factors of residential electricity demand is relatively perfect. Lee et al. (2013) $)^{[1]}$ found that the urbanization level, urban residents consumption level, industrialization degree, nationalization degree, opening up degree and technological innovation ability are the main reasons for the regional differences in China's energy consumption. Lee et al. $(2015)^{[2]}$ research found that water and drought disaster factors, temperature factors, economic growth factors and regional factors are the main factors that affecting china's residents living energy consumption. Han (2015) ${ }^{[3]}$ simply divided the factors affecting the monthly electricity consumption of urban and rural residents into direct factors and indirect factors. The former included the total population of the whole society, the proportion of urban residents and weather, etc., while the latter included the growth rate of industrial added value, the number of employed people, the price of all kinds of energy and investment, etc. Lin et al $(2016)^{[4]}$ found that residents' electricity consumption depends mainly on the increase in household income, urbanization and other factors resulting in the use of household appliances and the increase in the length of use.

At present, scholars have applied different types of model methods in the verification process of influencing factors of residential electricity demand. Zhu et al. (2014) ${ }^{[5]}$ used LMDI method to decompose the growth of domestic electricity consumption in China based on such factors as population effect, urbanization effect, social atomization effect and electricity intensity effect. Han et al. (2015) ${ }^{[3]}$ first established four different types of basic prediction models with conventional methods by analyzing various influencing factors and the availability of monthly data, and then introduced particle swarm optimization algorithm to establish PSO prediction model. Xiang et al. $(2017)^{[6]}$, based on the questionnaire survey on the domestic electricity consumption of residents in Beijing, Hangzhou, Guangzhou and Guiyang, focused on analyzing the influencing factors of electricity consumption, the degree to which electricity price adjustment affects residents' electricity demand and the tendency of energy saving behavior. Wang et al. (2018) ${ }^{[7]}$ put forward a circular neural network prediction model based on the backward propagation algorithm of time series decomposition, and analyzed the characteristics of electricity consumption. Yang et al. $(2020)^{[8]}$ incorporated the level of economic development, climatic conditions, residents' lifestyle and consumption habits into the factors affecting the energy consumption of the country's residents, and established a regression model to obtain China's per capita energy consumption in 2025.

\section{Analysis of trend}

\subsection{Analysis of absolute trend and relative trend of residential electricity sales}

From the perspective of absolute quantity, residents' demand for electricity in Hunan province has increased sharply in recent years. From the annual electricity sales data, compared with 2010, the annual electricity sales of urban and rural residents in 2018 increased by 1.95 times. As shown in Fig. 1, residential electricity sold presents an obvious 
seasonal fluctuation trend, with a large fluctuation range, but generally shows a jumping upward trend. From the perspective of relative quantity, the proportion of electricity sold by urban and rural residents in the total electricity sold increased from 2010 to 2018. Among them, the proportion of residential electricity sold rose slowly from 2010 to 2013, and the range of residential electricity sold changed from $10-15 \%$ to $15-20 \%$ in $2014-2015$, achieving a phased leap, and the proportion of residential electricity sold remained in the same range from 2016 to 2019 .

\subsection{Analysis of residential electricity sales and average temperature trend}

Fig. 2 shows the trend of electricity sales and monthly average temperature for urban and rural residents from 2010 to 2018. Of urban and rural residents can be seen from the diagram, the whole electricity on the rise, but in the same year and there is an obvious seasonal fluctuation. The peak of electricity generally appears in the high-temperature months (July to September) and low-temperature months (December to February), while low in spring and autumn season. Therefore, urban and rural residents of electricity demand is highly correlated to the temperature status. Compared with low-temperature months, residents' electricity sales in high-temperature months increase more obviously. This is mainly because in hightemperature weather, urban residents use air conditioning for refrigeration for a long period of time, resulting in a large scale of electricity consumption, while rural residents need to use water pumps to irrigate farmland.

In general, with the development of economy and the continuous improvement of people's living standard, the demand for electricity maintains a trend of steady growth. However, it can be found from the above figure that there is indeed a correlation between the daily electricity sales of urban and rural residents and the temperature, but it is not a coordinated relationship in step. In other words, other important factors besides the temperature still affect the daily electricity sales of urban and rural residents. Therefore, this paper further analyzes other possible influencing factors and explores the consumption electricity sales of urban and rural residents through modeling.

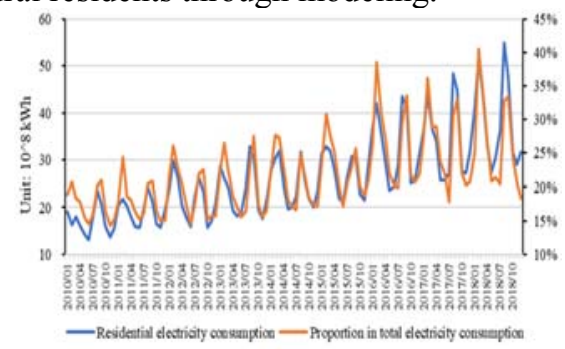

Fig. 1. Residential electricity consumption and its proportion in total electricity consumption

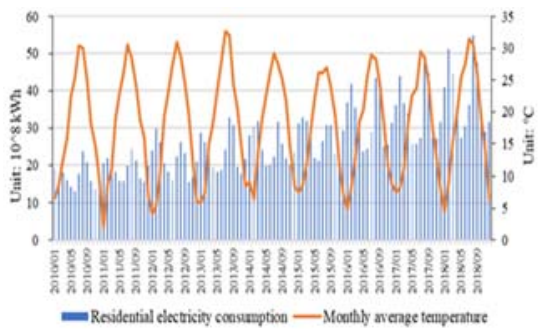

Fig. 2. Trend of residential electricity consumption and monthly average temperature

Data source: State Grid Hunan Electric Power Company Limited; China Weather

\section{Empiric study}

This paper uses the monthly data from January 2014 to June 2019 from wind database, CSMAR database and Hunan statistical yearbook. Among them, the explanatory variables are the daily electricity sales of urban and rural residents in Hunan province(10000kWh), and the explanatory variables are the days of climate discomfort in Hunan province(monthly), the per capita disposable income of urban and rural residents(yuan), the cross term of average high temperature and precipitation( $\mathrm{mm})$, the cross term of average low temperature and 
relative precipitation in Hunan province, and the dummy variable of high and low temperature months in Hunan province. Among the external factors, temperature is the most important factor.

The most important factor in electricity sales. Relevant literature shows that the comfortable temperature of human body in the air is between $13^{\circ} \mathrm{C}$ and $25^{\circ} \mathrm{C}$. in this paper, the sum of the days with the maximum temperature higher than $25^{\circ} \mathrm{C}$ or the minimum temperature lower than $13^{\circ} \mathrm{C}$ in each month is defined as non-comfortable days. The increase of household electricity consumption will directly affect household electricity sales. This paper uses per capita disposable income of Hunan province to describe household income. Considering the impact of precipitation on the real body temperature, the cross terms of average high temperature and precipitation, and average low temperature and precipitation are included in the model to explore the heterogeneity of the impact of precipitation on Residents' electricity sales under high temperature and low temperature. Moreover, the electricity sales of residents in Hunan province showed a cyclical change, and the model introduced dummy variables representing high temperature months (June to August) and low temperature months (December to February).

Through the discussion of the above variable selection, the multiple regression model between urban and rural residents' electricity sales and explanatory variables is constructed as follows:

$$
\begin{gathered}
\text { ln rele }=\beta_{0}+\beta_{1} \text { ln } d p i+\beta_{2} \text { ncd }+\beta_{3} \text { aht } * \text { raf }+\beta_{4} \text { alt } * \text { raf }+\beta_{5} \text { htemp } \\
+\beta_{6} \text { ltemp }+u
\end{gathered}
$$

Among them, rele represents the electricity sales of urban and rural residents in Hunan province, $d p i$ represents the per capita disposable income of urban and rural residents, $n c d$ represents the days of monthly climate discomfort, aht and alt represent the average high temperature and low temperature, raf represents the precipitation, htemp and ltemp represent the dummy variables of high and low temperature months respectively.

\section{Results \& Analysis}

Based on the above model and data, this paper uses stata15.1 software to get the results shown in Table 1.

\begin{tabular}{|c|c|c|c|c|}
\hline Variables & $\begin{array}{l}\text { Model } 1 \\
\text { ln rele }\end{array}$ & $\begin{array}{l}\text { Model } 2 \\
\text { ln rele }\end{array}$ & $\begin{array}{l}\text { Model } 3 \\
\text { ln rele }\end{array}$ & $\begin{array}{l}\text { Model } 4 \\
\text { ln rele }\end{array}$ \\
\hline $\ln d p i$ & $\begin{array}{c}0.595^{* * *} \\
(0.104)\end{array}$ & $\begin{array}{c}0.514 * * * \\
(0.0872)\end{array}$ & $\begin{array}{c}0.553 * * * \\
(0.0930)\end{array}$ & $\begin{array}{c}0.492 * * * \\
(0.0926)\end{array}$ \\
\hline$n c d$ & & $\begin{array}{c}0.0193 * * * \\
(0.00346)\end{array}$ & $\begin{array}{c}0.0198^{* * *} \\
(0.00358)\end{array}$ & $\begin{array}{c}0.00999 * * \\
(0.00431)\end{array}$ \\
\hline$a h t * r a f$ & & & $\begin{array}{c}9.06 \mathrm{e}-05 \\
(0.000101)\end{array}$ & $\begin{array}{c}0.000276^{* *} \\
(0.000109)\end{array}$ \\
\hline alt*raf & & & $\begin{array}{l}-9.85 \mathrm{e}-05 \\
(0.000123)\end{array}$ & $\begin{array}{c}-0.000337 * * \\
(0.000136)\end{array}$ \\
\hline htemp & & & & $\begin{array}{c}0.279 * * * \\
(0.0855)\end{array}$ \\
\hline ltemp & & & & $\begin{array}{c}0.200 * * * \\
(0.0750)\end{array}$ \\
\hline $\mathrm{R}^{2}$ & 0.337 & 0.556 & 0.571 & 0.650 \\
\hline
\end{tabular}

Table 1. stepwise regression results of urban and rural residents' electricity consumption.

Notes: Standard deviations are in parentheses, and the confidence levels are*** $\mathrm{p}<0.01,{ }^{* *} \mathrm{p}<0.05,{ }^{*}$ $\mathrm{p}<0.1$.

With the gradual inclusion of explanatory variables, $\mathrm{R}^{2}$ increased significantly, which means that the explanatory variables selected by the model are representative. From model 
$4, \mathrm{R}^{2}$ has reached 0.65 , which shows that the change of explanatory variables can explain $65.0 \%$ of the fluctuation of urban and rural residents' electricity sales, and the explanatory power is good. From the perspective of each explanatory variable, for every $1 \%$ increase in per capita disposable monthly income, the domestic electricity sales of urban and rural residents will increase by $0.49 \%$. For each additional day of non-comfort days per month, the domestic electricity sales of urban and rural residents will increase by $0.01 \%$. The cross term of average high temperature and precipitation is significant at the significance level of 0.05 , which means that in the high temperature state, with the increase of precipitation by $1 \mathrm{~mm}$, the domestic electricity sales of urban and rural residents increase by $0.000276 \%$. In the same way, in the low temperature state, for every millimetre increase in precipitation, the domestic electricity sales of urban and rural residents decreased by $0.000337 \%$. In addition, the difference in dependent variable between high temperature month (July to September) and other months is 0.279 , which means that other factors remain unchanged. The domestic electricity sales of urban and rural residents in high temperature month is $0.279 \%$ higher than that in other months. Similarly, the electricity sales of urban and rural residents in low temperature months are $0.200 \%$ higher than those in other months.

\section{Conclusion \& Enlightenment}

In this paper, the urban and rural residents' electricity sales from January 2014 to June 2019 are taken as the explanatory variables to establish a multiple linear regression model and explore its influencing factors. The results show that the per capita disposable monthly income $(d p i)$, days of discomfort $(n c d)$, the cross term of average high temperature and precipitation, the cross term of average low temperature and precipitation, the variables of high temperature month and low temperature month all significantly affect the electricity sales of urban and rural residents in Hunan province. Specially, for every $1 \%$ increase in dpi or for each additional day of non-comfort days per month, the domestic electricity sales of urban and rural residents will increase by $0.49 \%$ or $0.01 \%$. In addition, under high temperature and low temperature conditions, the influence of precipitation presents asymmetric characteristics. Combined with the above analysis, the Enlightenment of this paper is as follows. First, power grid enterprises should pay more attention to urban and rural residents' electricity sales as the analysis object when making power development planning in Hunan province. Second, when studying the objective law of urban and rural residents' domestic electricity demand, we should fully consider the impact of various economic and non-economic factors, and judge the future changes of residents' electricity demand on the basis of scientific prediction of various influencing factors.

\section{References}

1. B. Lee, Q. B. Lee, Resources Science, 6, 1194(2013).

2. S. S Lee, Q. Zhang, Economic Survey, 2, 19(2015).

3. F. W. Han, Statistics and Decision, 2, 94(2015).

4. B. Q. Lin, C. Liu, Economic Research Journal, 10, 69(2016).

5. K. Zhu, H. T. Yin, Electric Power, 3, 130 (2014).

6. N. Xiang, F. Xu, Chinese Journal of Population Resources and Environment, 1,216(2017).

7. X. Q. Wang, Y. L. Chen, Q. Yang, H. C. Liu, Computer Engineering and Applications, 20, 230(2018).

8. J. Yang, K. Ninab. P. C. Lee, M. Liu, R. Liu, H. H. Chen, Energy of China, 42, 8(2020). 